\title{
Analytical Research on Deformation Monitoring of Large Span Continuous Rigid Frame Bridge during Operation
}

\author{
Aicheng Shan \\ School of Civil Engineering \& Architecture, Chongqing Jiaotong University, Chongqing, China \\ Email: 995064489@qq.com
}

Received 24 May 2015; accepted 9 August 2015; published 12 August 2015

Copyright (C) 2015 by author and Scientific Research Publishing Inc. This work is licensed under the Creative Commons Attribution International License (CC BY). http://creativecommons.org/licenses/by/4.0/

(c) (i) Open Access

\begin{abstract}
Based on a large span continuous rigid frame bridge in Chongqing of China, the main pier vertical displacement and deviation, the bridge deck alignment and the expansion joint deformation are analytically researched during operation. Firstly, the monitoring content and method of the large span continuous rigid frame bridge are clearly stated. Secondly, by finite element software Midas Civil, the relevant deformation values of the bridge are calculated. Thirdly, in practice, the relevant deformation values of the bridge are measured. Finally, the measured values in practice are compared with the calculated ones by the finite element software Midas Civil, finding that the former is less than the latter, and it can be concluded that the bridge is basically in the normal working condition. In this paper, the analytical research on the deformation monitoring can provide the basis for similar bridges, which has good practical significance.
\end{abstract}

\section{Keywords}

Continuous Rigid Frame Bridge, Deformation Monitoring, Main Pier Vertical Displacement and Deviation, Bridge Deck Alignment, Expansion Joint Deformation

\section{Introduction}

In recent years, with the rapid economy development, the span of Chinese bridges is increasing. Among these bridges, the continuous rigid frame bridge is one main form of long span bridges.

The continuous rigid frame bridge is of widespread popularity because of the continuous property of its upper structure, its long span, the low difficulty of its construction, the driving comfort, its easy maintenance, its low cost and so on [1]. Nevertheless, a number of factors, such as the increasing traffic, the overloaded vehicles and 
the natural aging of the structure materials, cause the large deformation of the bridge, which will have an influence on the safety, durability and driving comfort of the bridge. Therefore, it is of high importance to carry out the bridge deformation monitoring [2] [3].

The excessive mid-span deflection is the main reason for the accident of the continuous rigid frame bridge during operation. According to the long-term measured deflection data of the Humen Bridge auxiliary channel bridge - a long span continuous rigid frame bridge, Peijin Wang established the finite element model and accurately predicted long-term creep deformation after completion. Further, the long-term growing deflection coefficient was obtained. His achievements provide the basis for the long-term deflection prediction of similar bridges [4].

For long-span continuous rigid frame bridge deformation monitoring, related researches were carried on at home and abroad [5]-[17]. Based on long-term monitoring result of long-span rigid frame bridge, Xinhong Yuan got the bridge deformation law and the characteristics of the stress and strain during operation. Then the calculation model of the bridge was established, analyzing the influence of the different specifications, load age, concrete shrinkage and creep in relative humidity environment, and loss of prestress on the deformation. It summarized deformation law and the influencing factors of deformation, but safety assessment was not done for deformation.

Based on a long-span continuous rigid frame bridge, this paper has determined the content and method of deformation monitoring according to the relevant specification [18]-[25]. Through the finite element software Midas Civil, the calculated value of deformation monitoring has been obtained, which is compared with the measured value, getting the relevant conclusion about deformation monitoring. The deformation monitoring analysis of the long-span continuous rigid frame bridge can provide a certain basis for similar bridges, which has good practical significance.

\section{Project Profile}

The long-span continuous rigid frame bridge is located in Chongqing section of Shanghai-Chengdu Expressway, which is a two-parallel bridge. The total length is $750 \mathrm{~m}$ and the main bridge is $612 \mathrm{~m}$ long. For the main bridge, the upper structure is a prestressed concrete continuous rigid frame bridge. Full bridge span is: $5(4) \times 30 \mathrm{~m}$ (prestressed concrete continuous T-beam) $+(110+200+110) \mathrm{m}$ (prestressed concrete continuous rigid frame +4 $\times 40 \mathrm{~m}$ (continuous prestressed concrete T-beam). The single width bridge is $12.00 \mathrm{~m}$ wide, and the lateral arrangement is as follows: $0.50 \mathrm{~m}$ (crash barrier) $+11.00 \mathrm{~m}$ (roadway) $+0.5 \mathrm{~m}$ (crash barrier).

Main bridge upper structure adopts cast-in-place concrete box girder whose section is a single box single room variable cross-section. The beam in the pivot is $11.57 \mathrm{~m}$ high and the one in the mid-span is $3.50 \mathrm{~m}$ high. The height of the beam adopts 1.5 times parabola. The bottom slab in the pivot is $1.20 \mathrm{~m}$ thick and the one in the mid-span is $0.32 \mathrm{~m}$ thick. The thickness of the bottom slab adopts linear gradient. Around the top of the pier, the thickness of web is $1.20 \mathrm{~m}$. The other webs thickness adopts three levels $(70 \mathrm{~cm}, 60 \mathrm{~cm}$ and $50 \mathrm{~cm})$. The width of the top slab is $12.10 \mathrm{~m}$, the one of the bottom slab is $7.00 \mathrm{~m}$ and the one of the flange slab is $2.55 \mathrm{~m}$. The box girder roof sets one-way cross-sectional slope of 2.0\%. A single width sets nine diaphragm plates.

Among the bottom structure, main piers and transition piers are reinforced concrete cross-section hollow piers, bored piles foundation with pile caps. The surfacing layer of the bridge deck pavement adopts $10 \mathrm{~cm}$ thick asphalt concrete.

The bearings of the main bridge adopt GPZ pot rubber bearing, which are set at 5\# and 8\# pier, each place setting 2 sets of GPZ5DX unidirectional sliding bearings (single width). For the main bridge, at the end of two side spans, SSFB240 type expansion joints are respectively set.

For the main bridge, the box girder adopts C50 concrete, the bridge deck pavement leveling layer, bent caps, piers, prefabricated T-beams of the approach bridges adopt C40 concrete and the crash barriers adopt C25 concrete. The bridge design load is highway-grade I.

The bridge elevation layout is shown in Figure 1.

\section{Deformation Monitoring Methods and Measuring Point Arrangement}

According to the bridge situation, the study monitored the horizontal control network, vertical control points, main pier deformation, bridge deck alignment and expansion joint deformation. 


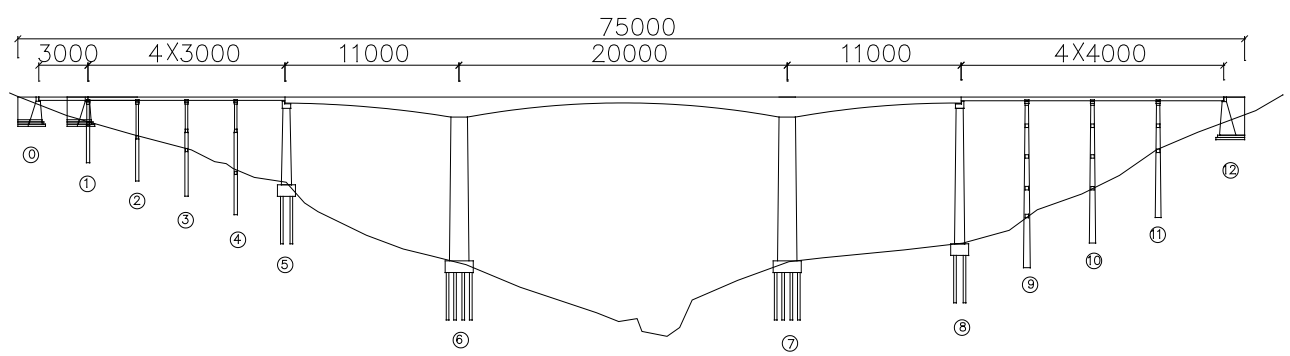

Figure 1. Bridge elevation layout (unit: $\mathrm{cm}$ ).

\subsection{Deformation Monitoring Methods}

\subsubsection{Horizontal Control Network}

The horizontal control network is set up by triangulation network. A Leica TCR1201 total station (Grade 1") with optical prism is used directly on the middle of base. According to the second level horizontal control network technology in "Building Deformation Measurement Procedures" (JGJ8-2007), the horizontal control network monitoring data are achieved, measured by traverse survey method.

\subsubsection{Vertical Control Points}

Vertical datum points are measured by NA2 Leica precise level (Accuracy of $0.1 \mathrm{~mm}$ ) with the invar rod. According to the national second level measurement method, all observation leveling lines are formed into closed ones. The station observation sequence, observation method, return measure and so on are carried out according to "the National First and Second Grade Leveling Specification” (GB/T 12897-2006).

\subsubsection{Pier Deformation Monitoring}

The Leica TCR1201 total station (Grade 1") with optical prism is used to monitor the pier deformation. According to the secondary plane accuracy requirement in "Building Deformation Measurement Procedures" (JGJ82007), the polar method is adopted for measurements. The main pier vertical deformation is in accord with the relevant bridge deck linear point.

\subsubsection{Bridge Deck Alignment Monitoring}

The precision level with the invar rod is used to measure the bridge deck alignment according to the second level observation.

The sight length of leveling, distance between the front and rear sight and the precision level repeated measurement times all conform to the specification requirements for "secondary precision level". Before the measurement, the "I" angle of level should be checked first. The datum point and the bridge linear observation points should form a closed loop, the observation sequence is "back-front-front-back" for the odd station and "front-back-back-front" for the even station. Then the observation data should be adjusted.

\subsubsection{Expansion Joint Deformation Monitoring}

Expansion joint deformation monitoring includes both sides (large stake mark side and small stake mark side) deck transverse displacement monitoring of expansion joints and steel gap change monitoring of expansion joints. A total station with optical prism is used to measure both sides deck transverse displacement and the steel tap is used to measure the steel gap change.

\subsection{Measuring Point Arrangement}

\subsubsection{Arrangement Principle}

Screen dots of deformation monitoring network are divided into the datum points, the work basis points and deformation observation points. The layout should follow the following principles:

1) Datum points: Steady and reliable locations should be chosen outside of the deformation area, and each bridge should have at least three datum points;

2) Work basis points: The points should be stable and easy to use; 
3) Deformation observation points: The points should be set up in the locations which can reflect the detection deformation characteristics or in the test section.

\subsubsection{Measuring Point Arrangement}

1) Horizontal control network

Three points which can reflect the characteristics of the detection plane or are in the detection section are selected as the measuring points.

2) Vertical control points

Two points which can reflect the elevation characteristics or are in the detection section are selected as the measuring points.

3) Main pier deformation

For deformation monitoring of the main piers, 8 observation points are laid, 2 points laid at each pier, which are respectively arranged at the 0 \# block diaphragm center and the outside of left, right width piers. Measuring point numbers of the left width 5\# pier are D5-1 and D5-2, and measuring point numbers of the left width 6\# pier are D6-1 and D6-2. Measuring point numbers of the right width 6\# pier are D6-3 and D6-4, and measuring point numbers of the right width 7\# pier are D7-3 and D7-4. The total station reflector plates are directly pasted on the surface of concrete as observation points. Measuring point arrangement is shown in Figure 2 and Figure 3 below.

4) Bridge deck alignment

The bridge deck alignment monitoring points make full use of the historical monitoring points, and some measuring points are added to meet the requirements of measurement gap. Specific arrangement of measuring

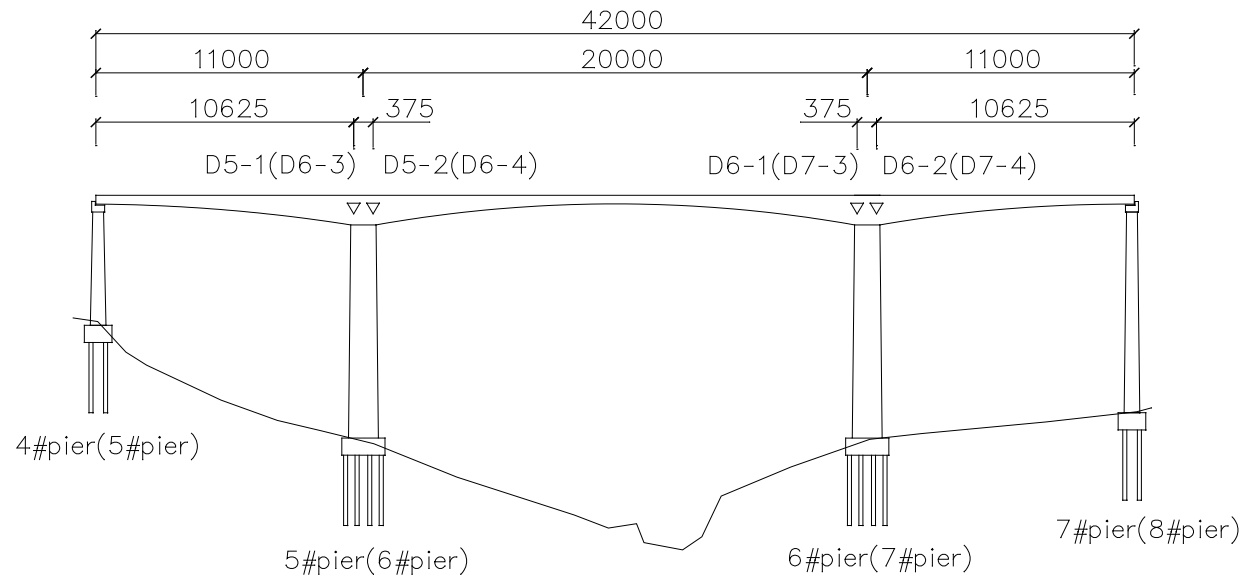

Figure 2. The longitudinal arrangement of deformation measuring points in main pier (unit: $\mathrm{cm}$ ).

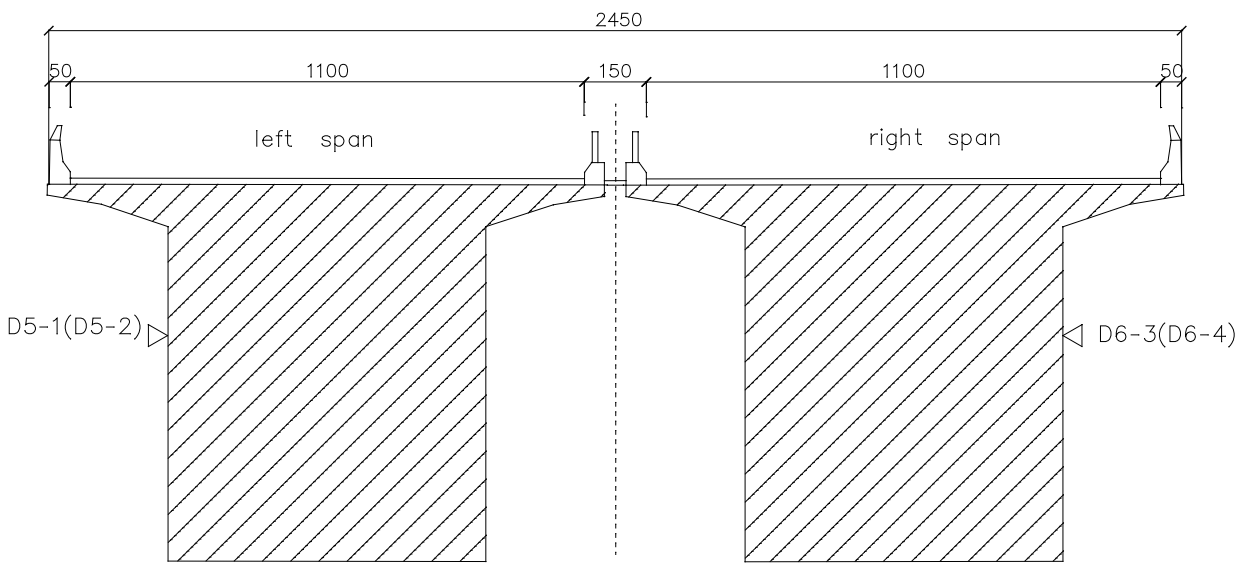

Figure 3. The transversal arrangement of deformation measuring points in main pier (unit: $\mathrm{cm}$ ). 
points is as follows: The bridge deck alignment monitoring only aims at the main bridge alignment. The longitudinal measuring point arrangement is at the mid-span of main bridge, the maximum displacement points, $\mathrm{L} / 4$, pivot of the side span. Also, according to the requirements of not more than $20 \mathrm{~m}$ stationing spacing, linear observation points are added.

The linear observation points of transverse direction are set on the bridge deck crash barrier inner side bottom of the right and left width and on the inner side top of median strip concrete fence base. 4 vertical sections are set for linear observation points, which are left outside (L), left inside (L'), right inside (R) and right outside (R'). The bridge sets 116 deck linear observation points in total. The observation points adopt stainless steel round head testing nails, which are anchored by anchor adhesive after drilling holes and are marked with red oil paint. Measuring point arrangement is shown in Figure 4 and Figure 5.

5) Expansion joint deformation

There is one observation section set in each expansion joint of the main bridge for this expansion joint monitoring. Points are laterally set on the outside of the deck. Each observation section has two measuring points. There are four observation sections and eight measuring points in total. Measuring point arrangement is shown in Figure 6. In this figure, B, B1, B2 and B3 are the longitudinal distance of expansion joint, measured by the steel ruler.

\section{Monitoring Results and Analysis}

\subsection{Deformation Monitoring Calculation for Model}

According to the main material parameters and load conditions of the bridge, based on the "General Code for

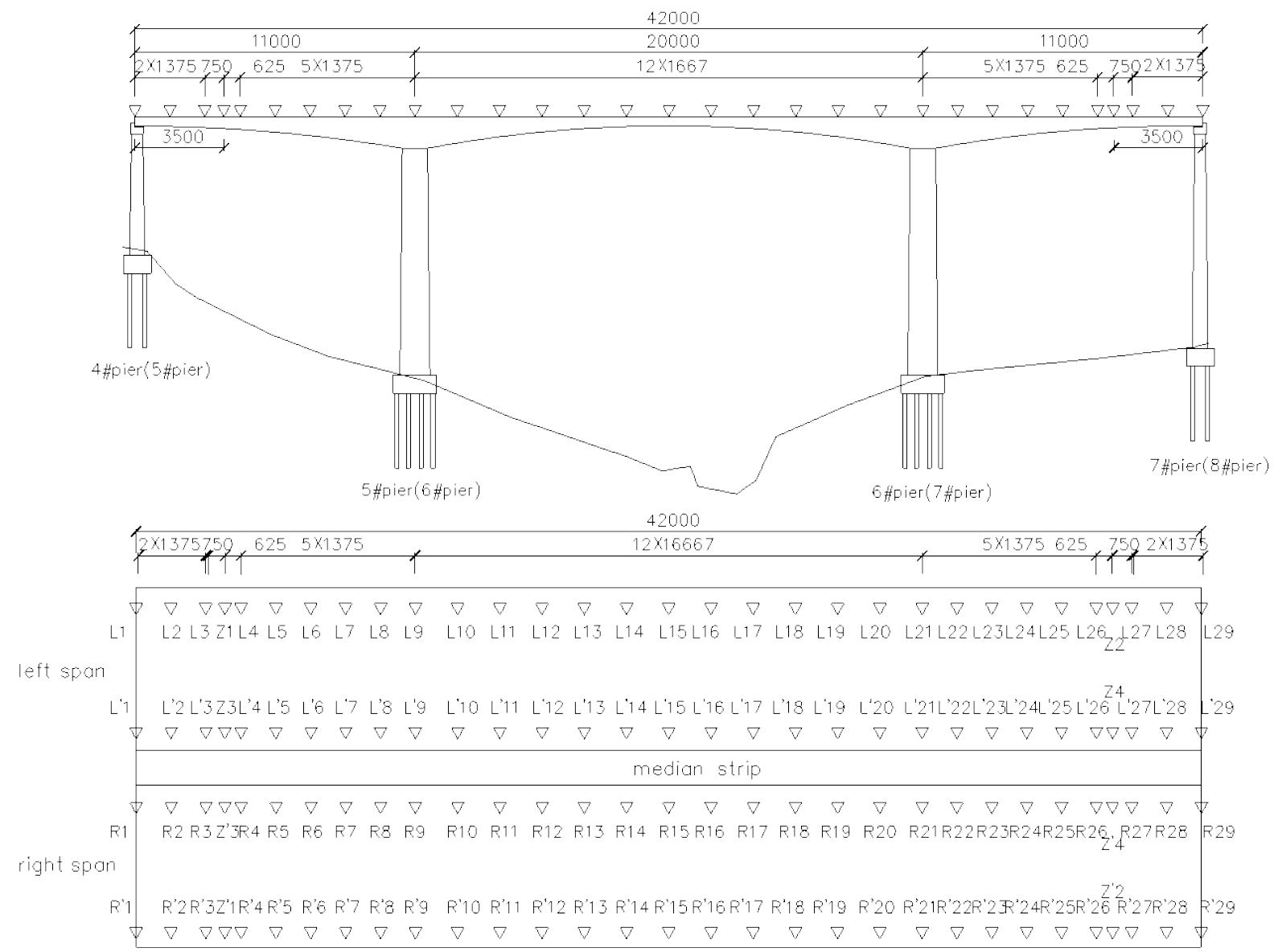

Annotation: Z1 - Z4 and Z'1 - Z'4 signify the maximal displacement points on side spans

Figure 4. The longitudinal and plane arrangement of the bridge deck linear measuring points (unit: $\mathrm{cm}$ ). 
Design of Highway Bridges and culverts” (JTG D60-2004) and "General Code for Design of Highway Reinforced Concrete and Prestressed Concrete Bridges and culverts" (JTG D62-2004), the finite element analysis software Midas Civil is used to model. The main beam and piers are simulated by beam elements. There are 193 nodes and 190 units in total. Because of being closed to traffic in the process of monitoring, the model does not consider the vehicle load effect. The considered bridge load types mainly include concrete creep and shrinkage, the loss of prestress, the temperature change and so on. In view of the bridge final internal force condition decided by the bridge construction steps and technology, according to the designed construction steps, the construction stage analysis is carried out in the calculation. The structure discrete figure is shown in Figure 7.

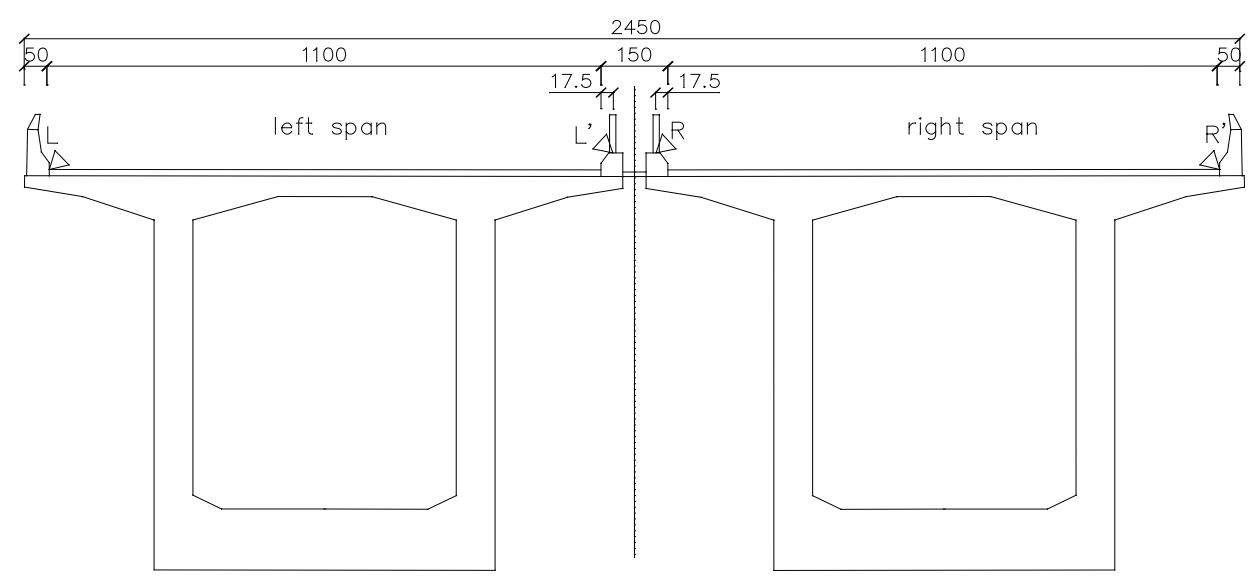

Figure 5. The transversal arrangement of the bridge deck linear measuring points (unit: $\mathrm{cm}$ ).

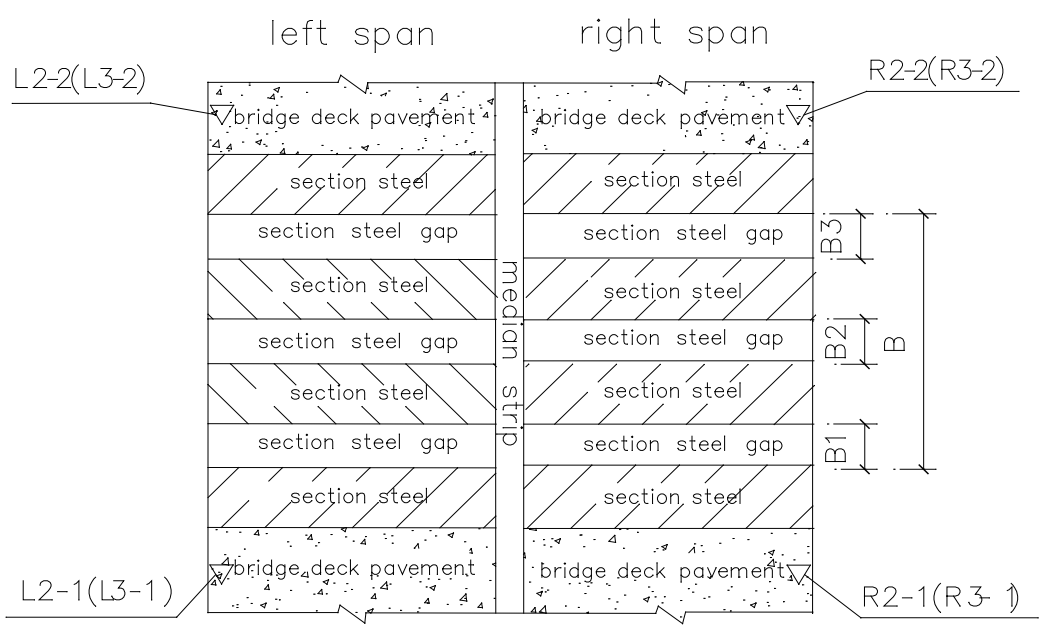

Figure 6. Monitoring points arrangement on expansion joint deformation.

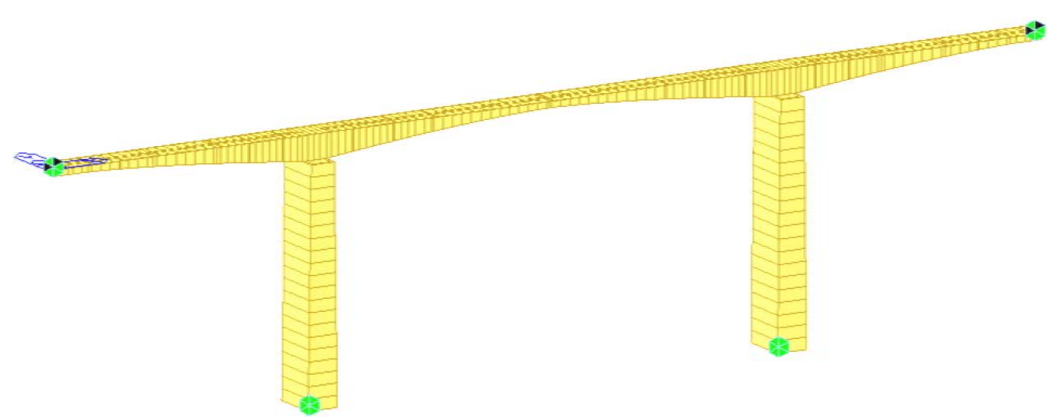

Figure 7. Structure discrete model of the main bridge. 
Through the model calculation and analysis, the calculated values of the main pier deformation, bridge deck alignment and expansion joint deformation can be obtained.

\subsection{Comparative Analysis of Calculated and Measured Values}

The calculation values are obtained by the finite element software Midas Civil. According to the bridge monitoring content and method, the bridge deformation measured values can be obtained and compared with the calculated values. The comparative analysis results of the main pier deformation, the bridge deck alignment and the expansion joint deformation are as follows:

\subsubsection{Comparative Analysis of Main Pier Vertical Displacement Results}

In order to know the main piers settlement situation and its influence on the bridge deck alignment in the monitoring period, the main pier vertical displacements are measured. "Measured main pier vertical displacements" is obtained by "the relative elevations in the second period (December 2012) minus the ones in the first period (September 2012)". "Calculated main pier vertical displacements" is the model calculated values considering the overall cooling and shrinkage creep. "Negative main pier vertical displacements" means the downward deformations. Comparison results of measured and calculated values are shown in Table 1.

From the test results of the main pier vertical displacement observation points, the following results can be obtained: When the temperature of the left width drops $9.5^{\circ} \mathrm{C}$, the vertical displacement of $5 \#$ pier is $9.86 \mathrm{~mm}$, less than calculated value $10.13 \mathrm{~mm}$; The vertical displacement of $6 \#$ pier is $9.00 \mathrm{~mm}$, less than calculated value $10.44 \mathrm{~mm}$. When the temperature of the right width drops $11.7^{\circ} \mathrm{C}$, the vertical displacement of 6\# pier is 9.97 $\mathrm{mm}$, less than calculated value $12.15 \mathrm{~mm}$; the vertical displacement of $7 \#$ pier is $11.85 \mathrm{~mm}$, less than calculated value $12.52 \mathrm{~mm}$.

The above analysis shows that the measured vertical displacement of each main pier is less than the calculated value, which can determine that there was no obvious settlement deformation for each main pier in the monitoring period.

\subsubsection{Comparative Analysis of Main Pier Deviation Results}

In order to know each main pier deviation situation in the monitoring period, the main pier displacements along the bridge longitudinal direction are measured. "Measured main pier longitudinal displacements" is the bridge axis direction conversion values according to the measured points displacement in the first and the second period. "Calculated main pier longitudinal displacements" is the calculated values considering the overall cooling and shrinkage creep. "Positive main pier longitudinal displacement" means the rightward displacement. Comparison results of measured and calculated values are shown in Table 2 and Table 3.

From the test results of the main pier observation points, the following results can be obtained: When the temperature of the left width drops $17.7^{\circ} \mathrm{C}$, the longitudinal displacement towards the river of $5 \#$ pier top is 12 $\mathrm{mm}$, less than calculated value $15.55 \mathrm{~mm}$; The longitudinal displacement towards the river of $6 \#$ pier top is 13 $\mathrm{mm}$, less than calculated value $15.88 \mathrm{~mm}$. The specific longitudinal displacement sketch of main piers on left width is shown in Figure 8. When the temperature of the right width drops $17.2^{\circ} \mathrm{C}$, the longitudinal displacement towards the river of 6\# pier top is $8 \mathrm{~mm}$, less than calculated value $15.20 \mathrm{~mm}$; The longitudinal displacement towards the river of $7 \#$ pier top is $12 \mathrm{~mm}$, less than calculated value $15.52 \mathrm{~mm}$. The specific longitudinal displacement sketch of main piers on right width is shown in Figure 9. The above analysis shows that the measured deviation of each main pier is less than the calculated value, which can determine that the main pier deviation

\begin{tabular}{|c|c|c|c|c|c|}
\hline $\begin{array}{l}\text { Measured } \\
\text { points }\end{array}$ & Locations & $\begin{array}{l}\text { Relative elevations in } \\
\text { the 1st period (m) }\end{array}$ & $\begin{array}{l}\text { Relative elevations in } \\
\text { the } 2 \text { nd period (m) }\end{array}$ & $\begin{array}{l}\text { Measured vertical } \\
\text { displacements (mm) }\end{array}$ & $\begin{array}{l}\text { Calculated vertical } \\
\text { displacements (mm) }\end{array}$ \\
\hline L9 & 5\# pier top, left width & 103.39423 & 103.38437 & -9.86 & -10.13 \\
\hline L21 & 6\# pier top, left width & 105.59655 & 105.58755 & -9.00 & -10.44 \\
\hline R9 & 6\# pier top, right width & 95.41096 & 95.40099 & -9.97 & -12.15 \\
\hline R21 & 7\# pier top, right width & 97.59195 & 97.58010 & -11.85 & -12.52 \\
\hline
\end{tabular}


Table 2. Comparison between the calculated and practical longitudinal displacement values of main piers on left width (unit: mm).

\begin{tabular}{ccccc}
\hline $\begin{array}{c}\text { Measured } \\
\text { points }\end{array}$ & Locations & $\begin{array}{c}\text { Measured longitudinal } \\
\text { displacements }\end{array}$ & Measured mean values & $\begin{array}{c}\text { Calculated longitudinal } \\
\text { displacements }\end{array}$ \\
\hline D5-1 & 5\# pier small stake mark side & 11 & 12 & 15.55 \\
D5-2 & 5\# pier big stake mark side & 13 & -13 & -15.88 \\
D6-1 & 6\# pier small stake mark side & -11 & \\
D6-2 & 6\# pier big stake mark side & -15 & \\
\hline
\end{tabular}

Table 3. Comparison between the calculated and practical longitudinal displacement values of main piers on right width (unit: mm).

\begin{tabular}{cccc}
$\begin{array}{c}\text { Measured } \\
\text { points }\end{array}$ & Locations & $\begin{array}{c}\text { Measured longitudinal } \\
\text { displacements }\end{array}$ & $\begin{array}{c}\text { Measured mean values } \\
\text { displacements }\end{array}$ \\
\hline D6-3 & 6\# pier small stake mark side & 7 & 8 \\
D6-4 & 6\# pier big stake mark side & 9 & 15.20 \\
D7-3 & 7\# pier small stake mark side & -12 & -12 \\
D7-4 & 7\# pier big stake mark side & -12 & -15.52 \\
\hline
\end{tabular}

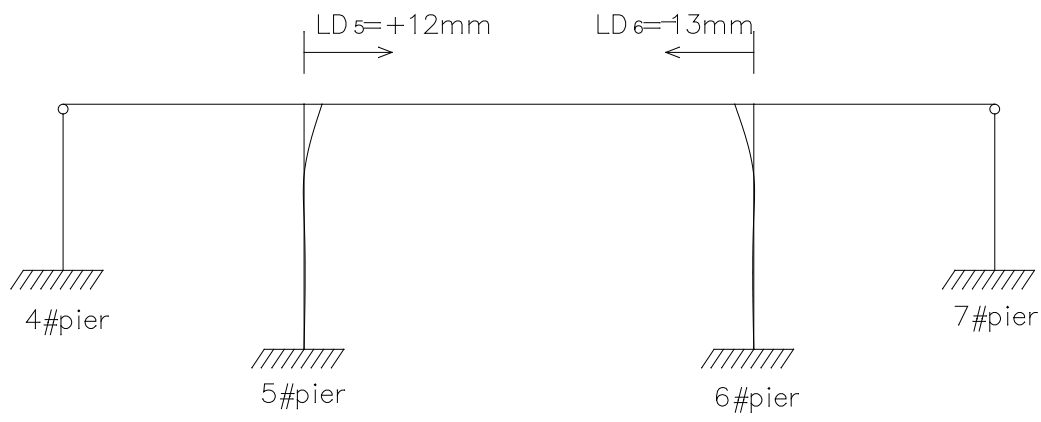

Figure 8. The longitudinal displacement sketch of main piers on left width.

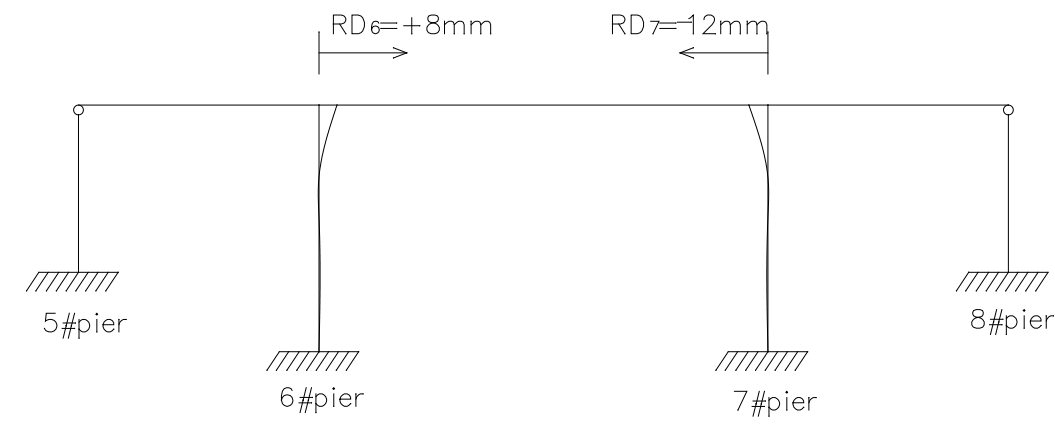

Figure 9. The longitudinal displacement sketch of main piers on right width.

was within the security scope in the monitoring period.

\subsubsection{Comparative Analysis of the Bridge Deck Alignment Deflection Results}

Analyzing comparatively two period measured results, "Measured deflections" is obtained by "the relative elevations in the second period minus the ones in the first period”. Negative value represents downwarping. "Calculated deflections” is the model calculated values considering the comprehensive influence of the overall cool- 
ing and shrinkage creep on the bridge deck alignment. According to the main pier vertical displacement monitoring, it can be concluded that there was no settlement for the bridge main pier. Thus, the measured deflections and the calculated deflections can be compared, which is shown in Figure 10, Figure 11.

From above, for the bridge left width outside deck, the measured maximum deflection is $19.98 \mathrm{~mm}$ (downward) at the 7L/12 section of $6 \#$ span. For the left width inside deck, the measured maximum deflection is 19.39 $\mathrm{mm}$ (downward) at the 5L/12 section of $6 \#$ span. For the right width outside deck, the measured maximum deflection is $23.44 \mathrm{~mm}$ (downward) at $\mathrm{L} / 2$ section of $7 \#$ span. For the right width inside deck, the measured maximum deflection is $23.11 \mathrm{~mm}$ (downward) at 7L/12 section of $7 \#$ span.

As shown in Figure 9, Figure 10, the inside and outside deflection change rule of the bridge left and right width is basically consistent with the calculated deflection curve. The measured deflection curve is relatively smooth, of no obvious mutation. The measured deflections are less than the calculated values except the individual non-critical section measuring points of the right width inside.

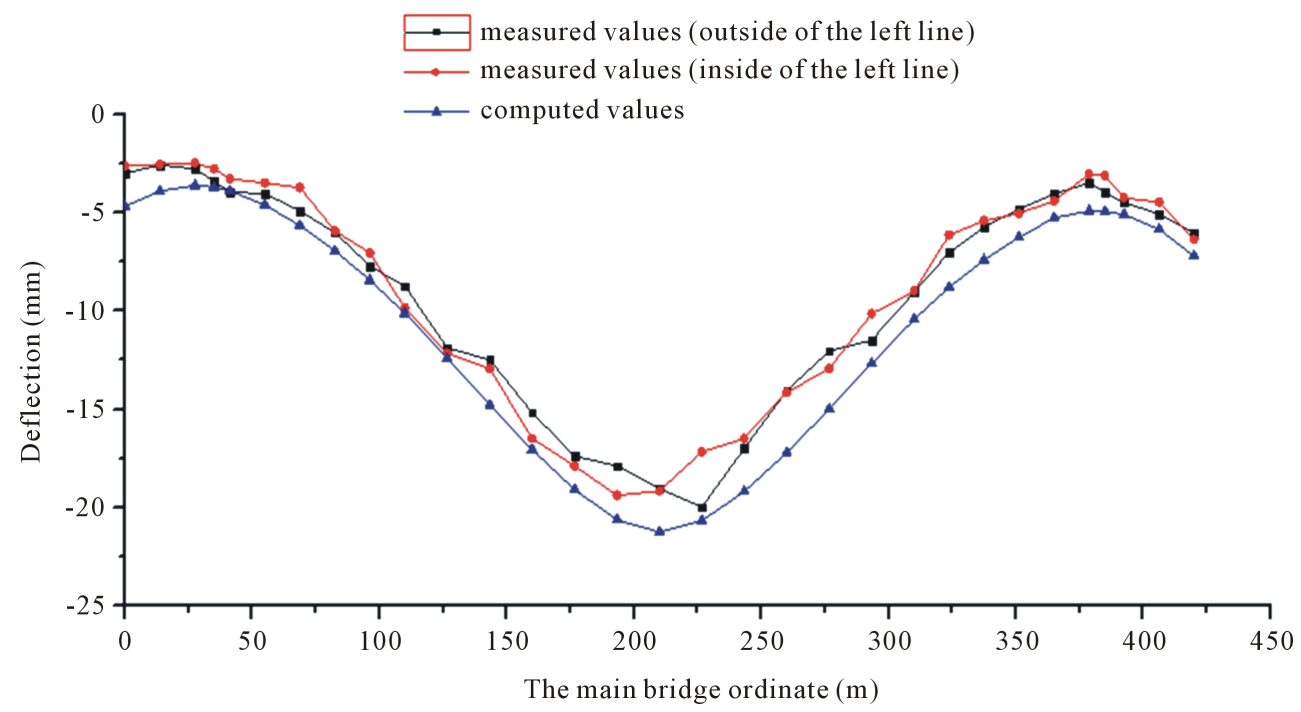

Figure 10. Comparison between the calculated and measured (including inside and outside) deflection values of the left line.

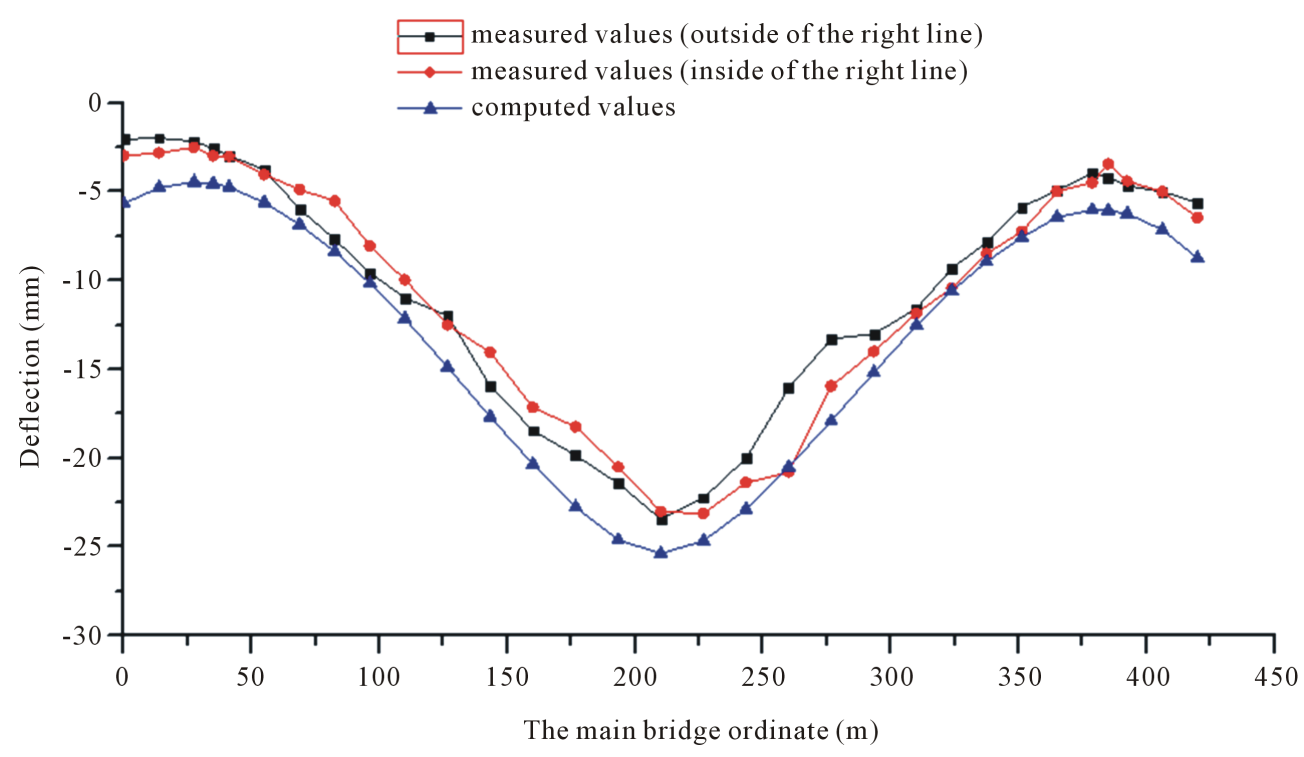

Figure 11. Comparison between the calculated and measured (including inside and outside) deflection values of the right line. 
Table 4. Comparison on theoretical and practical expansion joint clearance of main piers (unit: mm).

\begin{tabular}{ccccc}
\hline Width sort & $\begin{array}{c}\text { Expansion joint } \\
\text { serial number }\end{array}$ & $\begin{array}{c}\text { Deformation measured } \\
\text { by total station }\end{array}$ & $\begin{array}{c}\text { Deformation measured } \\
\text { by steel tape }\end{array}$ & $\begin{array}{c}\text { Calculated } \\
\text { deformation }\end{array}$ \\
\hline \multirow{2}{*}{ Left width } & L2\# & 44 & 44 & 47.44 \\
Right width & L3\# & 49 & 49 & 51.68 \\
& R2\# & 43 & 43 & 48.68 \\
\hline
\end{tabular}

\subsubsection{Comparative Analysis of the Expansion Joint Deformation Results}

By the total station and steel tape, four expansion joints gap measured values of the bridge left and right width are compared with the calculated values. "The measured deformation" is calculated according to measured data of 1st and 2nd period by the total station and steel tape. "Calculated of deformation" is obtained by modeling calculation on the basis of the actual cooling. The results are shown in Table 4.

From measured results, the width of each expansion joint shows the expanding trend on the cooling condition. When the temperature of left width drops $17.7^{\circ} \mathrm{C}$, the L2\# expansion joint had an expansion of $44 \mathrm{~mm}$, and the L3\# expansion joint had an expansion of $49 \mathrm{~mm}$, both less than the calculated value. When the temperature of right width drops $17.2^{\circ} \mathrm{C}$, the R2\# expansion joint had an expansion of $43 \mathrm{~mm}$, and the R3\# expansion joint had an expansion of $46 \mathrm{~mm}$, both less than the calculated value. All expansion joints are in normal work condition. By contrast, for the left width, the expansion of L2\# expansion joint is less than the one of L3\# expansion joint. For the right width, the expansion of R2\# expansion joint is less than the one of R3\# expansion joint.

\section{Conclusions}

Compared the field measured data with the calculated data by finite element software Midas Civil, the following conclusions can be obtained:

1) For the long-span continuous rigid frame bridge, each main pier measured vertical displacement is less than the calculated value, thus it can be initially determined that, there was no obvious settlement for each main pier during the monitoring period.

2) For each main pier, the measured deviation value is less than the calculated value, which shows that the measured stiffness for each main pier is bigger than calculation stiffness and each main pier deviation is within the security scope.

3) The inside and outside deflection change rule of the bridge left and right width is basically consistent with the calculated deflection curve. The measured deflection curve is relatively smooth, of no obvious mutation. The measured deflections are less than the calculated values except the individual non-critical section measuring points of the right width inside.

4) In the field, the main bridge expansion joint deformation measured values are less than the calculated values and each expansion joint is in good working condition.

5) The bridge monitoring results shows that the bridge is basically in normal working condition.

Currently, the bridge is only monitored without moving load, assessing structural performance by the structure static deformation. It is advised that the main bridge health and safety monitoring system should be established at the right time. Adopting modern sensor technology, the structural responses (dynamic characteristics and vibration, dynamic strain, dynamic deflection and so on) under various environments should be monitored in real time during operation to obtain information reflecting structure condition and environment. Finally, the bridge structure condition can be comprehensively assessed.

\section{References}

[1] Fan, L.C. (2001) Bridge Engineering (Volume One). China Communications Press, Beijing.

[2] Chen, Z.S., Zhou, J.T., Zhang, C., Liu, S.M. and Song, J. (2013) Key Technology Research on External Prestressing Reinforced Concrete Arch Bridge. Journal of Chongqing Jiaotong University (Natural Science Edition) ISTIC, 32, 823-826.

[3] Liu, Q.Y. (2007) Study on Security Assessment Model of Stone Arch Bridge. Chongqing Jiaotong University, Chong- 
qing.

[4] Wang, P.J., Sheng, H.F. and Zhao, S.D. (2007) Long-Term Deflection Prediction Study on Prestressed Concrete Box Girder of Long-Span Continuous Rigid-Frame Bridge. Journal of Highway and Transportation Research and Development, 24, 87-89.

[5] Yuan, X.H. (2011) Study on Deformation of Long-Span Continuous Rigid Frame Bridge. Chang'an University, Xi'an.

[6] Yoshikawa, M., Hayashi, H., Kawakita, S., et al. (2000) Construction of Benten Viaduct, Rigid-Frame Bridge with Seismic Isolators at the Foot of Piers. Cement and Concrete Composites, 22, 39-46. http://dx.doi.org/10.1016/S0958-9465(99)00047-5

[7] Chen, Z., Zhang, C., Zhou, J., et al. (2013) Study of Cable Force of Construction Control and Alignment Control of Main Girders for Long-Span Railway Cable-Stayed Bridges. Modern Applied Science, 7, 47-56.

[8] Zengshun, C., Jun, S., Cheng, Z., et al. (2013) Study of Different Construction Processes Affecting the Installation of Appropriate Cambers for Long-Span Railway Cable-Stayed Bridges. Modern Applied Science, 7, 89-96.

[9] Ko, J.M. and Ni, Y.Q. (2005) Technology Developments in Structural Health Monitoring of large-Scale Bridges. Engineering Structures, 27, 1715-1725. http://dx.doi.org/10.1016/j.engstruct.2005.02.021

[10] Liu, S. and Zhao, Z. (2007) Deformation Monitoring of 70-m Span Box Girders of Hangzhou Bay Sea-Crossing Bridge at Construction Stage. World Bridges, 2, 018.

[11] Xu, J. and Xiang, H. (2000) Construction Control of Large Span Bridge. China Communications Press, Beijing.

[12] Gong, X. (2006) Research on the Main Girder Deflection of Long-Span Prestressing Concrete Continuous Girder Bridge. Southwest Jiaotong University, Chengdu.

[13] Zhang, K., Yan, G., Zhang, B. and Zhou, Z. (2010) Research on Stress, Deflection and Crack Monitoring System of Long-Span Continuous Rigid-Frame Bridge. Journal of Chongqing Jiaotong University (Natural Science Edition), 29, 521-524.

[14] Ohtsuki, A. and Ellyin, F. (2000) Large Deformation Analysis of a Square Frame with Rigid Joints. Thin-Walled Structures, 38, 79-91. http://dx.doi.org/10.1016/S0263-8231(00)00028-8

[15] Lan, Z., Zhou, J. and Zhou, Z. (2008) Study on Deflection On-Line Monitoring System of Box Girder Bridge. Journal of Chongqing Jiaotong University (Natural Science Edition), 27, 525-528.

[16] Sakano, M. and Wahab, M.A. (2001) Extremely Low Cycle (ELC) Fatigue Cracking Behavior in Steel Bridge Rigid Frame Piers. Journal of Materials Processing Technology, 118, 36-39. http://dx.doi.org/10.1016/S0924-0136(01)00857-3

[17] Huang, J., Wang, S., Liu, C., et al. (2003) The Necessity and Method of Main Girder Deformation Monitoring for Long-Span Continuous Rigid Frame Bridge during Construction. Bridge Construction, No. 1, 48-51.

[18] GB/T 12898-2006 (2006) Specifications for the First and Second Order Leveling. Standards Press of China, Beijing.

[19] GB50026-2007 (2007) Code for Engineering Surveying. China Planning Press, Beijing.

[20] JGJ 8-2007 (2007) Code for Deformation Measurement of Building and Structure. China Building Industry Press, Beijing.

[21] JT/T 327-2004 (2004) Highway Bridge Expansion and Contraction Installation. China Communications Press, Beijing.

[22] JTG H11-2004 (2004) Code for Maintenance of Highway Bridges and Culvers. China Communications Press, Beijing.

[23] JTG D60-2004 (2004) General Code for Design of Highway Bridges and Culverts. China Communications Press, Beijing.

[24] JTG D62-2004 (2004) Code for Design of Highway Reinforced Concrete and Prestressed Concrete Bridges and Culverts. China Communications Press, Beijing.

[25] JTG D63-2007 (2007) Code for Design of Ground Base and Foundation of Highway Bridges and Culverts. China Communications Press, Beijing. 